\title{
THE KNOWLEDGE OF AND ATTITUDES TOWARD ANAPHYLAXIS EMERGENCY MANAGEMENT AMONG POLISH DENTISTS
}

\author{
Piotr Ptaszynski ${ }^{1}$, Andrzej Raczynski ${ }^{2}$, Marcin Aluchna ${ }^{3}$, Alicja Aluchna ${ }^{4}$, Jacek Smereka ${ }^{2}$ \\ ${ }^{1}$ T. Marciniak Lower Silesian Specialist Hospital, Emergency Medicine Centre, Wroclaw, Poland \\ ${ }^{2}$ Department of Emergency Medical Service, Laboratory of Experimental Medicine and Innovative Technology, Wroclaw Medical University, \\ Wroclaw, Poland \\ ${ }^{3}$ Department of Conservative Dentistry, Medical University of Warsaw, Warsaw, Poland \\ ${ }^{4}$ Medical University of Warsaw, Warsaw, Poland
}

\begin{abstract}
INTRODUCTION: Anaphylaxis is a life-threatening medical emergency condition requiring immediate diagnosis and implementation of proper treatment. For the medical personnel facing a patient suspected of anaphylaxis, the necessary rapid initial management includes removing the allergen, calling for help, clearing the airway, laying the patient, and administering adrenaline in an intramuscular injection and oxygen. Airway management, intravenous access, and intravenous fluid challenge, as well as chlorphenamine and hydrocortisone injection, are also suggested if the medical personnel has appropriate skills and equipment available. Many studies emphasize that dentists feel inadequately trained to recognize and treat medical emergencies in dental offices, which especially refers to anaphylaxis. The aim of the study was to assess the dentists' preparedness, knowledge, and attitudes with regard to anaphylaxis in dental offices in Poland.
\end{abstract}

METHODS: The study was conducted between November 2016 and November 2017 during scientific meetings and congresses in Poland. The participants (Polish dentists) received information on the study objectives and voluntarily took part in the questionnaire survey. The questionnaire included 20 items concerning age, gender, work experience, specialization, latest training in cardiopulmonary resuscitation, onset time of allergic reaction, stridor, first line pharmacological treatment, route of administration and doses of adrenaline in different age groups, other medications recommended in anaphylaxis.

RESULTS: Overall, 500 active dentists working in Poland were offered to participate in the questionnaire study; 268 questionnaires were returned (53.6\%), including 18 partially filled. Finally, 250 questionnaires were further analyzed. The mean age of the participants was $42.33 \pm 10.53$ years, 226 (90.4\%) were female, and the mean work experience equaled $14.35 \pm 9.27$ years. The total of $28.8 \%$ of subjects attended cardiopulmonary resuscitation training within 12 months prior to the study, $38.40 \%$ within the previous $2-5$ years, $17.20 \%$ within the previous $6-10$ years, $8.00 \% 10$ or more years earlier, and $7.60 \%$ had never participated in such training since graduation. $24.4 \%$ of the participants stated that ingestion of food to which a patient was allergic resulted in severe anaphylactic reaction typically within 30 minutes, and $21.60 \%$ stated that in the case of contact with bee or wasp venom, severe anaphylaxis typically occurred within 10-15 minutes. Out of the study participants, $66.40 \%$ maintained that adrenaline was the first line drug in anaphylaxis; $27.2 \%$ indicated intramuscular route as the standard route for adrenaline injection in anaphylaxis; $46.4 \%$ pointed at the correct dose of adrenaline in anaphylaxis. The proper adrenaline dose in anaphylaxis for a 4 -year-old child was indicated by $42.00 \%$ and for a 10 -year-old child by $36.4 \%$. The correct dose of hydrocortisone in a 10 -year-old child was provided by $18.40 \%$. 
CONCLUSIONS: Among Polish dentists, the knowledge concerning the diagnosis and emergency treatment in anaphylaxis is low. Better postgraduate training including anaphylaxis management in dental offices should be recommended.

KEY WORDS: dentist, anaphylaxis, medical emergency, dental education

Disaster Emerg Med J 2018; 3(4): 126-130

\section{INTRODUCTION}

Anaphylaxis is a life-threatening medical emergency condition requiring immediate diagnosis and implementation of proper treatment. Local anesthesia is among the greatest risk factors for medical emergencies in a dental office, but cardiovascular disease and medical history also play a role [1]. Most dentists believe that local anesthetics are the main cause of anaphylactic reaction [2]; however, these properties were mostly attributed to preservatives (methylparaben and sulfites) and not the local anesthetic itself [3-5]. IgE-mediated systemic reactions, true anaphylaxis, may indeed occur after administration of local anesthetics, but this happens very rarely $[6,7]$. It should be noted that in a typical dental office, it is impossible to differentiate true anaphylaxis with IgE involvement from an anaphylactoid reaction, in which a similar clinical picture can occur but different mechanisms are involved [7].

The Australasian Society of Clinical Immunology and Allergy (ASCIA) guidelines for acute management of anaphylaxis suggest that the diagnosis of the condition is based on acute onset with typical skin features and involvement of respiratory and/or cardiovascular system and/or persistent severe gastrointestinal symptoms or any acute onset of hypotension or bronchospasm or upper airway obstruction where anaphylaxis is considered possible [8]. The European Academy of Allergy and Clinical Immunology Nomenclature Committee proposed the following definition of anaphylaxis: a severe, life-threatening, generalized or systemic hypersensitivity reaction characterized by rapidly developing life-threatening airways and/or breathing and/or circulation problems usually associated with skin and mucosal changes [9]. However precise the definition of anaphylaxis, it is not so important in clinical settings. For the medical personnel facing a patient suspected of anaphylaxis, the necessary rapid initial management includes removing the allergen, calling for help, clearing the airway, laying the patient, and administering adrenaline in an intramuscular injection (autoinjector, ampoules, or syringes) and oxygen $[6,8]$. Airway management, intravenous access, and intravenous fluid challenge, as well as chlorphenamine and hydrocortisone injection, are also suggested if the medical personnel has appropriate skills and equipment available [6].

Death due to anaphylaxis is most often related to airway compromise and cardiovascular collapse. Adrenaline is the first line drug in the emergency treatment of anaphylaxis. It is also a basic drug during cardiopulmonary resuscitation; however, the influence of adrenaline on the neurological outcome and return of spontaneous circulation in out-of-hospital cardiac arrest has been re-evaluated in recently published studies [10]. During cardiopulmonary resuscitation, the route of adrenaline injection is intravenous or intraosseous [11]. In anaphylaxis, it is recommended to inject the adrenaline intramuscularly in the anterolateral aspect of the middle third of the thigh, which is considered to be safe, easy, and effective $[6,12]$. This technique of intramuscular injection is easy to learn, and in most adults, an injection depth of $20 \mathrm{~mm}$ allows a safe adrenaline administration [13]. The intravenous route is reserved for medical personnel experienced in the titration of adrenaline [6]. The autoinjector systems usually provide $0.3 \mathrm{mg}$ of adrenaline per dose [1].

There are many causes of dental office anaphylaxis, including rare ones [7], but other substances and drugs used in general as well as in dental treatment, especially root treatment, should be taken into account [6]. Toletone et al. [14] emphasized the importance of investigating and awareness of risk factors in a dental office, including the rare causes of hypersensitivity reaction and severe anaphylactic life-treating reactions, such as chlorhexidine. Kleniewska et al. [15] described a case of a hairdresser allergic to persulphates who developed anaphylaxis being exposed to the same chemical present in dental cement during treatment in a dental office. The authors concluded that dentists should be aware of their patients' occupational allergies. An anaphylac- 
tic shock due to formocresol-soaked cotton pellet used during root canal treatment has also been described [16].

The European Resuscitation Council (ERC) guidelines suggest that every dentist should participate in basic life support training and specialized training on recognition and management of medical emergencies [6]. The training should be refreshed every 1-2 years [17]. Dentists in Poland complete a 5-year undergraduate training including medical emergencies, emergency treatment, and basic/advanced life support practical training, but still, there is a concern among them about their practical skills and challenges they have to face in medical emergencies, especially in anaphylaxis $[18,19]$. Many studies emphasize that dentists feel inadequately trained to recognize and treat medical emergencies in dental offices, especially with reference to anaphylaxis [3].

The aim of the study was to assess the dentists' preparedness, knowledge, and attitudes regarding anaphylaxis in dental offices in Poland.

\section{Study participants \\ MATERIAL AND METHODS}

The study was approved by the institutional review board of the Polish Society of Disaster Medicine (approval No. 07.06.2016.IRB). It was conducted between November 2016 and November 2017 during scientific meetings and congresses in Poland. The participants (Polish dentists) received information on the study objectives and voluntarily took part in the questionnaire survey.

The questionnaire was developed by the authors: experienced paramedics, anesthesiologists, and dentists, and included 20 items referring to age, gender, work experience, specialization, latest training in cardiopulmonary resuscitation, onset time of allergic reaction, stridor, first line pharmacological treatment, route of administration and doses of adrenaline in different age groups, and other medications recommended in anaphylaxis.

\section{Statistical analysis}

Data were analyzed with the statistical package of Statistica 13.3 (TIBCO Software Inc., Tulsa, OK, USA). Descriptive statistics were used to analyze the demographic variables. Variability was measured with the standard deviation. The normality of variable distributions was tested with the Kolmogorov-Smirnov test and the homogeneity of variance with the Fisher-Snedcore F-test and the Levene test. A conventional significance level (alpha) equal to 0.05 was applied.

\section{RESULTS}

Overall, 500 active dentists working in Poland were offered to participate in the questionnaire study; 268 questionnaires were returned (53.6\%), including 18 partially filled. Finally, 250 questionnaires were further analyzed. The mean age of the participants was $42.33 \pm 10.53$ years, 226 (90.4\%) were female, and the mean work experience equaled $14.35 \pm 9.27$ years. Most subjects $(73.60 \%)$ worked in a private dental office, $29.60 \%$ in dental clinics with at least 2 dentists employed, $6.00 \%$ in hospitals.

The total of $28.8 \%$ of subjects attended cardiopulmonary resuscitation training within 12 months prior to the study, $38.40 \%$ within the previous $2-5$ years, $17.20 \%$ within the previous $6-10$ years, $8.00 \% 10$ or more years earlier, and $7.60 \%$ had never participated in such training since graduation. Lecture combined with practical manikin training was the most frequent type of cardiopulmonary resuscitation training $(64.00 \%)$, followed by lecture alone $(26 \%) ; 5.60 \%$ of the study participants declared no cardiopulmonary resuscitation training attended before the survey.

$24.4 \%$ of the participants stated that ingestion of food to which a patient was allergic resulted in severe anaphylactic reaction typically within $30 \mathrm{~min}$ utes, and $21.60 \%$ stated that in the case of contact with bee or wasp venom, severe anaphylaxis typically occurred within 10-15 minutes, $55.60 \%$ of the study subjects indicated that stridor occurred in anaphylactic shock during the inspiration phase. Out of the participants, $66.40 \%$ maintained that adrenaline was the first line drug in anaphylaxis, $24.8 \%$ pointed at hydrocortisone being also a first line drug of choice. The intramuscular route was indicated as the standard route for adrenaline injection in anaphylaxis by $27.2 \%$, intravenous route by $10.0 \%$, intramuscular or intravenous route by $30.40 \%$, intramuscular or subcutaneous route by $13.6 \%$, intramuscular, subcutaneous or intravenous route by $14.00 \%$. Overall, $46.4 \%$ pointed at the correct dose of adrenaline in anaphylaxis; however, $26.00 \%$ indicated $1 \mathrm{mg}$. The proper adrenaline dose in anaphylaxis for a 4-year-old child was indicated by $42.00 \%$ and for a 10 -year-old child by $36.4 \%$. The correct dose of hydrocortisone in a 10-year-old 
child was provided by $18.40 \%$. The correct time of adrenaline repeated dose in adult anaphylaxis was indicated by $36.40 \%$ of the study participants.

\section{DISCUSSION}

The emergency management in anaphylaxis depends on staff and equipment availability. Anaphylaxis in an operating theater with skilled medical personnel immediately available ends mostly with an excellent outcome [3]. With proper initial management and no delay in adrenaline administration, as well as oxygen availability, there is a high probability of good outcome without any further sequel $[3,6]$. That is why it is so important to prepare the equipment and medications properly, as well as implement appropriate medical training.

In the presented study, we revealed that a high percentage of dentists did not know the correct doses of adrenaline and routes of administration in different age groups in anaphylaxis. Çetinkaya et al. [2] assessed the knowledge of dentists on the symptoms and signs and correct treatment of anaphylaxis in dental offices in Istanbul, Turkey, using a 15-item anonymous questionnaire. They observed that none of the study participants was completely aware of the symptoms and signs of anaphylaxis; $48.8 \%$ knew that adrenaline was the first choice drug in anaphylactic shock and $55.6 \%$ had access to adrenaline in their dental offices, but only $1 / 3$ of the participants would choose the intramuscular route as the recommended way for adrenaline injection.

Krishnamurthy et al. [20] presented the results of a questionnaire study among dentists practicing in private clinics in Chennai, India. Only $28 \%$ of them were aware of the administration routes of drugs used in anaphylaxis; however, 62\% had emergency medicine kits in their dental offices.

In Slovenia, according to Umek and Sostaric [21], $3.1 \%$ of dentists reported anaphylaxis in their dental office, which translates into 0.03 case per dentist per year, and $9.7 \%$ of dentist over their entire career. On the Likert scale ranging from 1 (completely disagree) to 6 (completely agree), the study participants assessed their competence to diagnose anaphylaxis as 4.1 and to treat the condition as 4.8 .

In British dental practice, Girdler and Smith [22] observed that $0.9 \%$ of dentists reported anaphylaxis during dental treatment over a 12-month period. In the same study, it turned out that $38.0 \%$ of dentists felt competent to provide initial management in anaphylaxis, and $62.0 \%$ did not feel competent in the field.

In Brasil, Arsati et al. [23] studied dentists' attitude toward medical emergencies in the dental office. They revealed that $16.86 \%$ of the surveyed dentists had faced moderate allergic reactions within the previous 12 months, and anaphylaxis was reported by $0.40 \%$. In the same study, $72.9 \%$ of dentists turned out not competent to provide initial management in anaphylaxis, and only $1 / 4$ felt competent in this matter. The total of $22.7 \%$ of the surveyed dentists did not feel competent to perform the intramuscular injection and $61.4 \%$ - intravenous injection.

The final year dental students in New Zealand reported very low self-confidence with regard to medical emergencies (only $10.5 \%$ of them felt competent) [24]. In Saudi Arabia, only 35.5\% of the surveyed dentists in Riyadh felt competent to manage anaphylaxis in a dental office [25].

Oxygen plays an important role in the initial management of anaphylaxis. Several guidelines, including those by ERC and the Resuscitation Council UK, suggest that dentists should have immediate access to an automated external defibrillator and oxygen source; however, it is not obligatory in most European countries $[6,26]$. In Australia $63 \%$ and in Germany $70 \%$ of dentists have an oxygen source in their dental offices [27, 28]. Umek and Sostaric [21], using a questionnaire study, revealed that $49.1 \%$ of dental offices in Slovenia were equipped with an oxygen source.

An interesting study on possible cases of dental treatment-related death under local anesthesia in Japan was published in 2017 by Miyakoshi et al. [29]. They have analyzed 38 cases of death in Japan in the period of 1951-2014. Among them, in 8 cases anaphylaxis was the most probable cause of death (other causes were heart failure, cerebrovascular disorders, rhabdomyolysis, and unidentified in 11 cases). Loss of consciousness, nausea, respiratory arrest, and cardiac disorders were the most frequent first symptoms of adverse events [29]. In nearly every case, the onset time of the adverse event was less than 30 minutes after local anesthetic administration, and in most cases, lidocaine was used with or without vasoconstrictors.

It is very important to avoid any anaphylactic reaction triggers in dental treatment. A specialist in allergy can help exclude allergy to certain substances, such as those applied in dental treatment [4]. The suspicion of a possible anaphylactic reaction in the 
future means that the dental office must be carefully prepared for medical emergencies, including all necessary equipment, an oxygen source, and adrenaline, as well as a clear action plan [3]. In special cases, the patient should be treated in a well-equipped facility, sometimes even with the possibility of direct support from emergency medical personnel.

The high percentage of dentists who are unable to implement initial treatment in anaphylaxis is alarming, as it is a life-threatening condition.

\section{Study limitations}

The primary limitation is the nature of a questionnaire study. The participants could have misunderstood some questions, although the questionnaire was tested on a group of 30 dentists for the clarity of questions before creating the final version.

\section{Strengths of the study}

To the authors' best knowledge, it is the first study analyzing the self-assessed competence of dentists in Poland in the diagnosis and emergency treatment of anaphylaxis. The questionnaire used in the study included several aspects of diagnosis and emergency treatment in anaphylaxis in pediatric patients and adults.

\section{CONCLUSIONS}

The knowledge of Polish dentists concerning the diagnosis and emergency treatment of anaphylaxis is low. Better postgraduate training, including anaphylaxis management in the dental office, should be recommended.

\section{Conflict of interest}

The authors declare that they have no conflict of interest and the study was conducted without any commercial or financial relationships, without any financial support.

\section{Acknowledgments}

We would like to thank all the dentists who participated in the study for their cooperation, as well as the organizers of the congresses and courses who enabled the study to be performed during the events.

\section{REFERENCES}

1. Haas DA. Management of medical emergencies in the dental office: conditions in each country, the extent of treat- ment by the dentist. Anesth Prog. 2006; 53(1): 20-24, doi: 10.2344/0003-3006(2006)53[20:MOMEIT]2.0.C0;2, indexed in Pubmed: 16722281.

2. Çetinkaya F, Sezgin G, Aslan OM. Dentists knowledge about anaphylaxis caused by local anaesthetics. Allergol Immunopathol (Madr). 2011; 39(4): 228-231, doi: 10.1016/j.aller.2010.07.009, indexed in Pubmed: 21236550.

3. Maher NG, de Looze J, Hoffman GR. Anaphylaxis: an update for dental practitioners. Aust Dent J. 2014; 59(2): 142-8; quiz 273, doi: 10.1111/ adj.12161, indexed in Pubmed: 24861387.

4. Speca SJ, Boynes SG, Cuddy MA. Allergic reactions to local anesthetic formulations. Dent Clin North Am. 2010; 54(4): 655-664, doi: 10.1016/j.cden.2010.06.006, indexed in Pubmed: 20831929.

5. Becker DE, Reed KL. Local anesthetics: review of pharmacological considerations. Anesth Prog. 2012; 59(2): 90-102, doi: 10.2344/00033006-59.2.90, indexed in Pubmed: 22822998.

6. Truhlář A, Deakin CD, Soar J, et al. Cardiac arrest in special circumstances section Collaborators. European Resuscitation Council Guidelines for Resuscitation 2015: Section 4. Cardiac arrest in special circumstances. Resuscitation. 2015; 95: 148-201, doi: 10.1016/j. resuscitation.2015.07.017, indexed in Pubmed: 26477412.

7. Chiu CY, Lin TY, Hsia SH, et al. Systemic anaphylaxis following local lidocaine administration during a dental procedure. Pediatr Emerg Care. 2004; 20(3): 178-180, indexed in Pubmed: 15094577.

8. ASCIA guidelines for acute management of anaphylaxis. https://www. allergy.org.au/images/stories/pospapers/ASCIA_Guidelines_Acute_ Management_Anaphylaxis_2018.pdf.

9. Johansson SGO, Bieber T, Dahl R, et al. Revised nomenclature for allergy for global use: Report of the Nomenclature Review Committee of the World Allergy Organization, October 2003. J Allergy Clin Immunol. 2004; 113(5): 832-836, doi: 10.1016/j.jaci.2003.12.591, indexed in Pubmed: 15131563.

10. Perkins G, Ji C, Deakin C, et al. A Randomized Trial of Epinephrine in Out-of-Hospital Cardiac Arrest. New England Journal of Medicine. 2018; 379(8): 711-721, doi: 10.1056/nejmoa1806842.

11. Madziala M, Smereka J, Szarpak L. Pre-filled syringe as an option for drug delivery in emergency medicine. Disaster Emerg Med J. 2017; 2(2): 98-9.

12. Nanavati RS, Kumar M, Modi TG, et al. Anaphylactic shock management in dental clinics: an overview. J Int Clin Dent Res Organ. 2013; 5: 36-9.

13. Schneider TH, Emmel M, Daubländer M. Intramuskuläre Adrenalingabe durch Zahnärzte bei Anaphylaxie. Notfall Rettungsmedizin. 2010; 14(3): 211-216, doi: 10.1007/s10049-010-1363-2.

14. Toletone A, Dini G, Massa E, et al. Chlorhexidine-induced anaphylaxis occurring in the workplace in a health-care worker: case report and review of the literature. Med Lav. 2018; 109(1): 68-76, doi: 10.23749/ mdl.v109i1.6618, indexed in Pubmed: 29411737.

15. Kleniewska A, Wiszniewska M, Krawczyk-Szulc $P$, et al. Anaphylactic reaction in a hairdresser due to sensitization to persulphates. Occup Med (Lond). 2016; 66(7): 584-585, doi: 10.1093/occmed/kqw037, indexed in Pubmed: 27036150. 
16. Ding YJ, Song $\mathrm{H}$, Liu JH, et al. Brain injury due to anaphylactic shock as a result of formocresol used during root canal treatment. Int Endod J. 2013; 46(10): 999-1005, doi: 10.1111/iej.12092, indexed in Pubmed: 23506194.

17. Nogami K, Taniguchi S, Ichiyama T. Rapid Deterioration of Basic Life Support Skills in Dentists With Basic Life Support Healthcare Provider. Anesth Prog. 2016; 63(2): 62-66, doi: 10.2344/0003-3006-63.2.62, indexed in Pubmed: 27269662.

18. Smereka J, Aluchna M, Szarpak L. Availability of emergency medical equipment in dental offices in Poland: A preliminary study. Resuscitation. 2016; 106: e32, doi: 10.1016/j.resuscitation.2016.07.072.

19. Abelsson A. Learning through simulation. Disaster Emerg Med J. 2017; 2(3): 125-128, doi: 10.5603/DEMJ.2017.0027.

20. Krishnamurthy M, Venugopal NK, Leburu A, et al. Knowledge and attitude toward anaphylaxis during local anesthesia among dental practitioners in Chennai - a cross-sectional study. Clin Cosmet Investig Dent. 2018; 10: 117-121, doi: 10.2147/CCIDE.S159341, indexed in Pubmed: 29988726.

21. Umek N, Šoštarič M. Medical emergencies in dental offices in Slovenia and readiness of dentists to handle them. Signae Vitae. 2018; 14(1): 43-48, doi: 10.22514/sv141.032018.7.

22. Girdler NM, Smith DG. Prevalence of emergency events in British dental practice and emergency management skills of British dentists. Resuscitation. 1999; 41(2): 159-167, indexed in Pubmed: 10488938.
23. Arsati $F$, Montalli VA, Flório FM, et al. Brazilian dentists' attitudes about medical emergencies during dental treatment. J Dent Educ. 2010; 74(6): 661-666, indexed in Pubmed: 20516306.

24. Murray C, Chandler N. Final year dental students in New Zealand: Self-reported confidence levels prior to BDS graduation. N Z Dent J. 2016; 112(4): 116-121, indexed in Pubmed: 29694757.

25. Al-Hammad NS, et al. Medical emergencies in dental practices. Part II: Preparedness and readiness of Riyadh dentists. EC Dental Science. 2018; 17(4): 342-352.

26. Quality standards for cardiopulmonary resuscitation practice and training. Primary dental care - Quality standards. https://www.resus.org.uk/ quality-standards/primary-dental-care-quality-standards-for-cpr/. (2013).

27. Müller MP, Hänsel M, Stehr $S N$, et al. A state-wide survey of medical emergency management in dental practices: incidence of emergencies and training experience. Emerg Med J. 2008; 25(5): 296-300, doi: 10.1136/emj.2007.052936, indexed in Pubmed: 18434471.

28. Chapman PJ. A questionnaire survey of dentists regarding knowledge and perceived competence in resuscitation and occurrence of resuscitation emergencies. Aust Dent J. 1995; 40(2): 98-103, indexed in Pubmed: 7786237.

29. Miyakoshi M, Sato J, Wada M, et al. Possible cases of dental treatment-associated death under local anesthesia in Japan: A review of the literature. J Oral Maxillofac Surg. 2017; 29(4): 289-294, doi: 10.1016/j.ajoms.2017.02.005. 